\title{
Functional characterization of two CITED3 homologs (gcCITED3a and gcCITED3b) in the hypoxia-tolerant grass carp, Ctenopharyngodon idellus
}

\author{
Patrick KS Ng ${ }^{\dagger 2}$, Sung-Kay Chiu ${ }^{\dagger 1}$, Theresa FN Kwong1, Richard $\mathrm{MK} \mathrm{Yu}^{3}$, \\ Minnie ML Wong ${ }^{1}$ and Richard YC Kong*1
}

Address: ${ }^{1}$ Department of Biology and Chemistry, City University of Hong Kong, Kowloon Tong, Hong Kong Special Administrative Region, PR China, ${ }^{2}$ Department of Biochemistry, Chinese University of Hong Kong, New Territories, Hong Kong Special Administrative Region, PR China and ${ }^{3}$ School of Environmental and Life Sciences, University of Newcastle, New South Wales, Australia

Email: Patrick KS Ng - arshinghk@yahoo.com.hk; Sung-Kay Chiu - kaychiu@cityu.edu.hk; Theresa FN Kwong - theresa@cityu.edu.hk; Richard MK Yu - richard.yu@newcastle.edu.au; Minnie ML Wong - bhminnie@cityu.edu.hk; Richard YC Kong* - bhrkong@cityu.edu.hk

* Corresponding author †Equal contributors

Published: 3 November 2009

BMC Molecular Biology 2009, 10:101 doi:10.1186/1471-2199-10-101
Received: 4 August 2009

Accepted: 3 November 2009

This article is available from: http://www.biomedcentral.com/I47I-2/99/10/101

(C) $2009 \mathrm{Ng}$ et al; licensee BioMed Central Ltd.

This is an Open Access article distributed under the terms of the Creative Commons Attribution License (http://creativecommons.org/licenses/by/2.0), which permits unrestricted use, distribution, and reproduction in any medium, provided the original work is properly cited.

\begin{abstract}
Background: CITED proteins belong to a family of non-DNA-binding transcriptional coregulators that are characterized by a conserved ED-rich domain at the $\mathrm{C}$-terminus. This family of genes is involved in the regulation of a variety of transcriptional responses through interactions with the $\mathrm{CBP} / \mathrm{p} 300$ integrators and various transcription factors. In fish, very little is known about the expression and functions of CITEDs.
\end{abstract}

Results: We have characterized two closely related but distinct CITED3 genes, gcCited3a and gcCited $3 b$, from the hypoxia-tolerant grass carp. The deduced gcCITED3a and gcCITED $3 b$ proteins share $72 \%$ amino acid identity, and are highly similar to the CITED3 proteins of both chicken and Xenopus. Northern blot analysis indicates that the mRNA expression of gcCited $3 a$ and gcCited $3 b$ is strongly induced by hypoxia in the kidney and liver, respectively. Luciferase reporter assays demonstrated that both gene promoters are activated by gcHIF-I. Further, ChIP assays comparing normal and hypoxic conditions reveal differential in vivo binding of gcHIF-I to both gene promoters in kidney and liver tissues. HRE-luciferase reporter assays demonstrated that both gcCITED3a and gcCITED3b proteins inhibit gcHIF-I transcriptional activity, and GST pull-down assays confirmed that both proteins bind specifically to the $\mathrm{CHI}$ domain of the grass carp $\mathrm{p} 300$ protein.

Conclusion: The grass carp gCCITED $3 a$ and gCCITED $3 b$ genes are differentially expressed and regulated in different fish organs in response to hypoxic stress. This is the first report demonstrating in vivo regulation of two closely-related CITED3 isogenes by HIF-I, as well as CITED3 regulation of HIF-I transcriptional activity in fish. Overall, our findings suggest that unique molecular mechanisms operate through these two gcCITED3 isoforms that likely play an important regulatory role in the hypoxic response in the grass carp. 


\section{Background}

Cells and tissues respond to low oxygen levels by stabilizing the HIF-1 transcription factor, which controls the expression of over 100 different genes that are involved in adaptation and survival [1]. These include genes involved in erythropoiesis (e.g. EPO), vasculogenesis (e.g. VEGF), glucose metabolism (e.g. GLUT1 and GLUT4), and fibrogenesis. HIF-1 is a heterodimeric DNA-binding protein composed of an oxygen-sensitive HIF- $1 \alpha$ subunit and a constitutively expressed HIF-1 $\beta$ subunit (also known as the aryl hydrocarbon receptor nuclear translocator, or ARNT) [2]. In the presence of oxygen, HIF- $1 \alpha$ is hydroxylated by a prolyl hydroxylase [3]. This triggers its interaction with the pVHL protein, which targets HIF- $1 \alpha$ for degradation by the $26 \mathrm{~S}$ proteosome [4]. In the absence of oxygen, prolyl hydroxylase activity is inhibited. This results in the stabilization of HIF- $1 \alpha$ and the subsequent translocation of the HIF- $1 \alpha$ subunit into the nucleus where it binds HIF- $1 \beta$ and forms transcriptionally active HIF-1. HIF-1 regulates gene expression by interacting with sequence-specific hypoxia-responsive elements (HREs) found in either the 5'-flanking, 3'-flanking, or intronic regions of HIF-responsive genes. The HRE was first identified as a 256-bp sequence in the 3'-flanking region of the human EPO gene [5].

The CITED [CAMP-responsive element-binding protein (CBP)/p300-interacting transactivator with glutamic acid/ aspartic acid-rich tail] proteins belong to a family of transcriptional cofactors that is characterized by a conserved ED-rich domain at the C-terminus. The biological properties of CITED proteins include modulating a variety of cellular and developmental processes $[6,7]$ and responding to diverse biological [8] and environmental stimuli $[9,10]$. To date, four different CITED homologs have been reported in vertebrates. CITED2, which can function as an activator and a repressor depending on the tissue, is the most extensively studied of the four. In the initial description, CITED2 was shown to function as a repressor of hypoxia-inducible factor-1 (HIF-1) through competition for binding to the $\mathrm{CH} 1$ domain of $\mathrm{CBP} / \mathrm{p} 300$ [11]. The LPXL (Leu-Pro-X-Leu) motifs in both CITED2 and HIF-1 $\alpha$ interact with overlapping binding sites on the $\mathrm{CH} 1$ domain of p300 [12]. CITED2 has been reported to bind this same region with 33 -fold greater affinity than HIF- $1 \alpha$ [9]. Genetic evidence indicates that loss of CITED2 is associated with increased activation of HIF-1 target genes [13], supporting the hypothesis that CITED2 is a negative regulator of HIF-1 $\alpha$. Conversely, CITED2 functions as a COactivator for several transcription factors, such as AP-2 [14], PPAR- $\alpha$, and PPAR- $\gamma$ [15], by linking them to CBP/ p300. Cellular responses to TGF- $\beta$ are largely mediated by the Smad proteins, which serve as both transcription factors and transcriptional co-regulators. CITED2 is an important regulator of TGF- $\beta$ signaling through direct association with Smad2 and Smad3 [16]. Members of the CITED protein family may also play an important role in the regulation of reproductive functions. Studies have shown that CITED2 interacts with the LIM domain of the Lhx2 transcription factor to enhance transcription of the glycoprotein $\alpha$-subunit gene [17]. Furthermore, CITED1 has been shown to bind to the estrogen receptor ER- $\alpha$ and enhance the transcription of estrogen-inducible genes such as TGF- $\alpha$ [7].

CITED3 is the least studied member of the CITED family. Previous studies have shown that it is highly expressed during the early stages of embryonic development in the mesonephric tubules and eye in the chicken [18], the pronephros and eye in the frog [19], and the kidney of adult grass carp [20]. While much is known about the distribution and regulation of the CITED proteins in mammals, very little is known about these proteins in fish. Fish are ideal models to study molecular and cellular adaptation to hypoxia, as fluctuations in environmental oxygen availability have played an important role in the evolution of these animals [21]. The expression patterns and functions of the CITED proteins remain largely unknown in cyprinids. Our group has previously reported the presence of a hypoxia-responsive CITED3 cDNA in grass carp [20]. In an attempt to gain broader insights into the evolution and possible functions of the different CITED genes in fish, this study describes our findings on two closelyrelated but distinct CITED3 homologs - gcCITED3a and gcCITED3b - from the hypoxia-tolerant grass carp. We present evidence for a differential role of these two gcCITED3 genes for adaptation to hypoxia in grass carp based on their in vivo mRNA expression and response pattern to short- and long-term hypoxia, as well as in vitro gene transactivation studies.

\section{Results \\ Identification of two CITED3 genes in grass carp}

We have previously described a full-length CITED3 cDNA from grass carp that shows high similarity to chicken and Xenopus CITED3 [20]. In this study, degenerate primers, targeting consensus sequences derived from a multiple alignment of the CITED3 open reading frames (ORFs) of grass carp [GenBank: AY225852], zebrafish [GenBank: AF359242], chicken [GenBank: AF261079] and Xenopus [GenBank: AI031460], were used for RT-PCR on total RNA extracted from the kidney of a grass carp that was exposed to hypoxia for $4 \mathrm{~h}$. A distinct cDNA fragment, cix1 $(0.7 \mathrm{~kb})$, with a partial ORF that shared high sequence identity with the grass carp CITED3 ORF was identified. Using 5'- and 3'-RACE PCR, a 3032-bp fulllength cDNA, CIX1, was obtained. DNA sequencing showed that CIX1 contains 5'- and 3'-untranslated (UT) regions of $122 \mathrm{bp}$ and $2187 \mathrm{bp}$, respectively, and an ORF (723 bp) that specifies a protein of 240 amino acids with 
a predicted molecular weight of $26.3 \mathrm{kDa}$. In agreement with this finding, a single mRNA transcript of approximately $3.0 \mathrm{~kb}$ was detected by Northern blot (data not shown). A pairwise sequence comparison demonstrated that CIX1 shares particularly high similarity with the CITED3 proteins of grass carp (72\%); zebrafish $(69.4 \%)$; and chicken (64.1\%), but only moderate similarity (42 $49 \%$ ) with the CITED2 protein, and low similarity $(<42 \%)$ with the CITED1 and CITED4 proteins from different vertebrate species. Moreover, the primary structure of the CIX1 and grass carp gcCITED3 [GenBank: $\underline{\mathrm{AAO} 48505}$ ] proteins contain the characteristic CR1, CR2, and CR3 domains that are highly similar to the homologous domains present in the chicken and Xenopus CITED3 proteins (Figure 1). Taken together, these data strongly suggest that CIX1 is a novel CITED3-like homolog. We refer to this gene as gcCited $3 b$, and the previously described gcCITED3 as gcCited $3 a$ [20]. This designation was chosen since the primary sequences and structures of these two homologs are most similar to known CITED3 proteins. The nucleotide sequence data of gcCited $3 a$ and gcCited $3 b$ have been deposited in the GenBank database as GenBank: AY225852 and GenBank: EU450668, respectively.

\section{Characteristics of the deduced gcCITED3a and gcCITED3b proteins}

Sequence alignment of the grass carp gcCITED3a and gcCITED3b proteins with homologs from pufferfish (Tetraodon nigrovindis), zebrafish (Danio rerio), Japanese

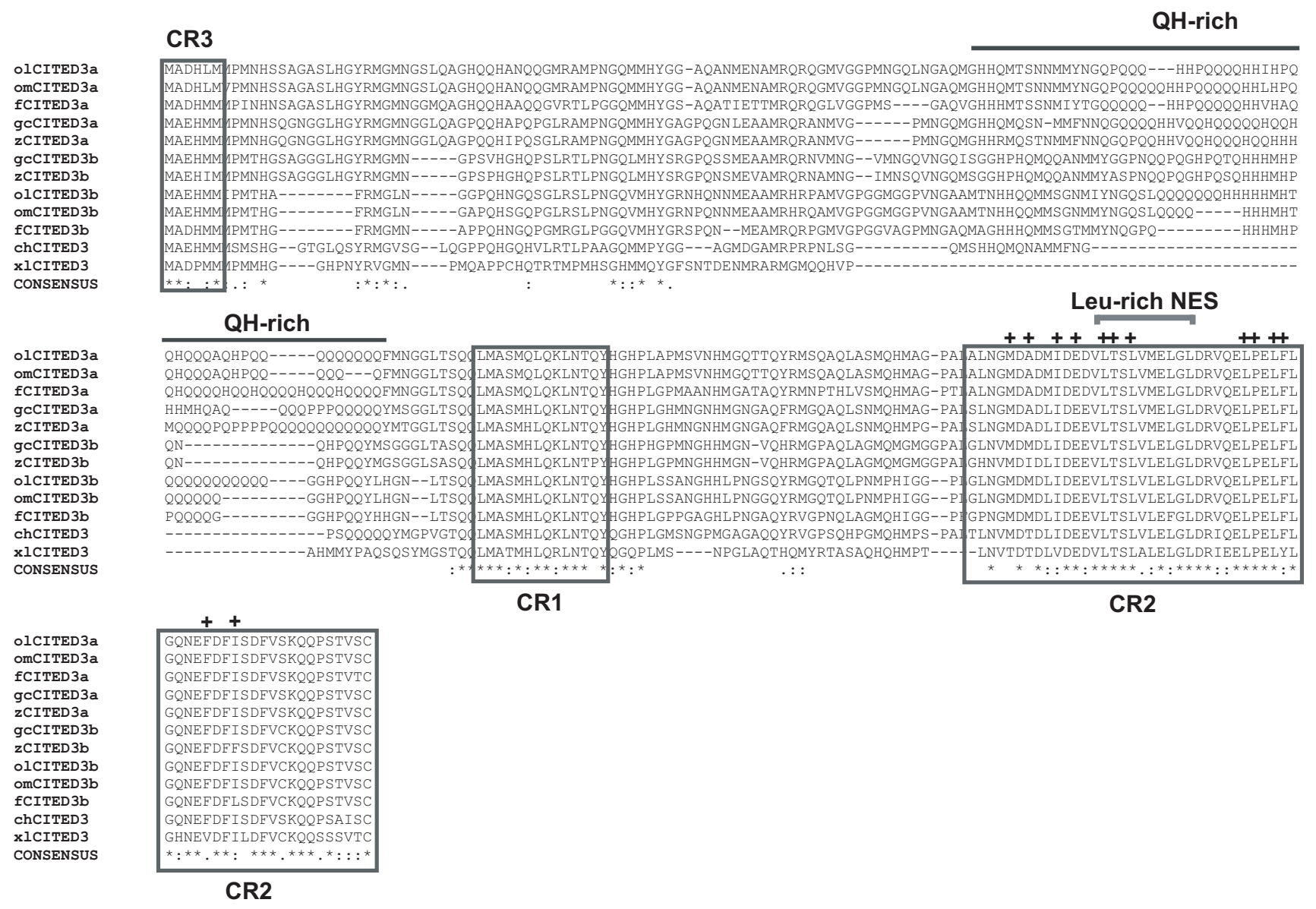

\section{Figure I}

Amino acid sequence alignment of gcCITED3a and gcCITED3b with related homologs from other fish species. Amino acid residues in the CRI, CR2 and CR3 conserved domains typically found in CITED proteins are boxed and labeled. Amino acid residues in the $\mathrm{CR} 2$ domain that interact with the $\mathrm{CHI}$ domain of $\mathrm{CBP} / \mathrm{p} 300$ are indicated with a plus $(+)$. The $\mathrm{QH}$ rich domain of fish CITED3a/CITED3b is highlighted by a grey overline. The leucine-rich nuclear export signal (Leu-rich NES) is indicated above the alignment with a parenthesis. olCITED3a and oICITED3b, Oryzias latipes CITED3a and CITED3b; omCITED3a and omCITED3b, Oryzias melastigma CITED3a and CITED3b; fCITED3a and fCITED3b, Fugu CITED3a and CITED3b; gcCITED3a and gcCITED3b, grass carp CITED3a and CITED3b; zCITED3a and zCITED3b, zebrafish CITED3a and CITED3b; xICITED3, Xenopus CITED3; chCITED, chicken CITED3. 
medaka (Oryzias latipes), marine medaka (Oryzias melastigma) and Fugu (Fugu rubripes) indicated extensive sequence similarity in the CR1, CR2, and CR3 domains (Figure 1). CR2 is the characteristic domain of the CITED protein family and is present in all known CITED proteins. Notably, a particularly high degree of sequence conservation is observed in the core CR2 motif, which is known to interact with the $\mathrm{CH} 1$ domain of the $\mathrm{p} 300 / \mathrm{CBP}$ co-transactivator [12]. Importantly, a glutamine and histidine-rich (QH-rich) region (amino acid positions 95 - 131 in gCCITED3a) is found only in the CITED3a and CITED3b homologs in fish but is absent in the chicken and Xenopus CITED3 (Figure 1), and mammalian CITED1, CITED2, and CITED4 proteins (data not shown). In addition, a leucine-rich nuclear-export signal (LMSLVVELGL), which presumably contributes to the sub-cellular localization of the CITED proteins [22], is also conserved within the CR2 domain of all the fish CITED3a and CITED3b proteins.

\section{Phylogeny of fish CITED3a and CITED3b proteins}

In silico screens of the zebrafish, Japanese medaka, Fugu genome and/or EST and NCBI GenBank databases identified a number of fish homologs that share substantial sequence similarity with the gcCITED3a and gcCITED $3 b$ proteins. Similar screens of various mammalian databases with CITED3, CITED3a, or CITED3b failed to identify any CITED3-like sequences, suggesting that these genes are absent in mammals. The phylogenetic relationship between different CITED3 proteins was analyzed by the neighbor-joining method using fish CITED1 proteins as the outgroup (see Table 1). As shown in Figure 2, CITED3 proteins are separated with high bootstrap support into three different sub-clades: fish-specific CITED3a and CITED3b, and avian/Xenopus CITED3.

\section{In vivo mRNA expression and response patterns of gcCITED3a and gcCITED3b to short- and long-term hypoxia}

To examine the in vivo expression pattern of gcCited $3 a$ and gcCited $3 b$ in response to hypoxia, grass carp $(n=3)$ were exposed to normoxia $\left(7.0 \mathrm{mg} \mathrm{O}_{2} / \mathrm{l}\right)$ and hypoxia $(0.5 \mathrm{mg}$ $\mathrm{O}_{2} / \mathrm{l}$ ) for $4 \mathrm{~h}$ and $96 \mathrm{~h}$. Total RNA was isolated from six different tissues (brain, gill, heart, kidney, liver, and muscle) of each fish at each time point for Northern blot analysis. Overall, the normoxic mRNA expression and hypoxic induction pattern of the gcCited $3 a$ and gcCited $3 b$ genes in different grass carp tissues were consistent between all three replicate blots, and a representative autoradiogram is shown in Figure 3. Under normoxic conditions, gcCited $3 a$ (1.6-kb mRNA) expression was detected in all tissues examined except muscle. After $4 \mathrm{~h}$ of hypoxia, a significant induction of $g c$ Cited $3 a$ was observed in the kidney, and a mild induction was identified in the gill and liver. The brain, heart, and muscle tissues showed no change in the expression of gcCited $3 a$. After $96 \mathrm{~h}$ of

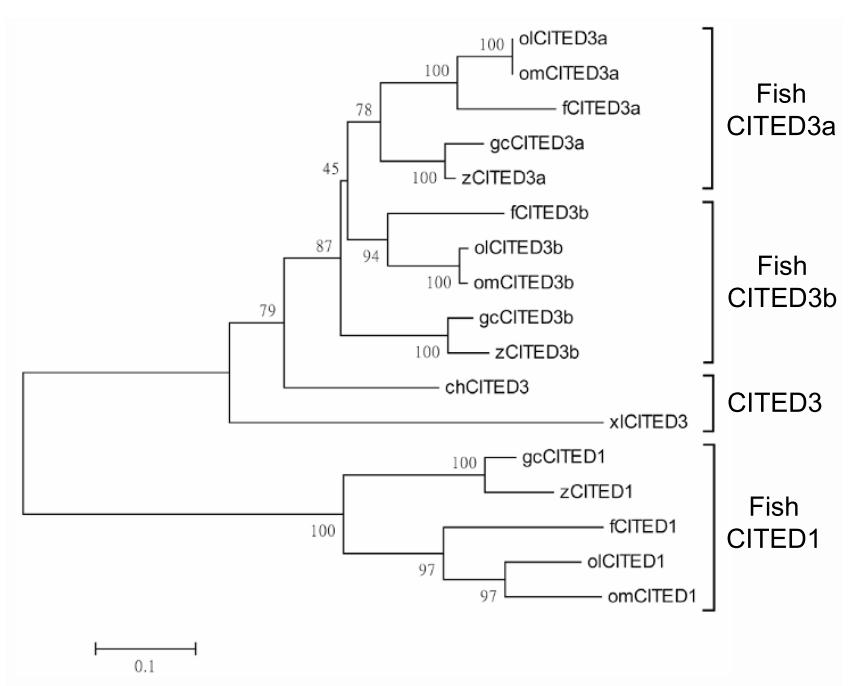

Figure 2

Phylogeny of fish gcCITED3a and gcCITED3b proteins. The tree was constructed by the neighbor-joining method of the MEGA v3.I program using fish CITEDI proteins as outgroup. The bootstrap support for each branch ( 1000 replications) is shown. The branch lengths are proportional to the number of substitutions between sequences. The GenBank/EMBL/Swissprot accession numbers of the CITED sequences used are given in Table I.

hypoxia, a marked induction of expression was observed in the kidney and liver, a modest induction was detected in the heart, and no change in gcCited $3 a$ expression was observed in the brain, gill, or muscle.

Under normoxic conditions, gcCited $3 b$ mRNA expression was also detected in all tissues examined except the muscle, and the highest level was detected in the kidney and liver. After $4 \mathrm{~h}$ of hypoxia, gcCited $3 b$ mRNA expression was induced in all tissues except the muscle. The highest induction was observed in the kidney and liver. After $96 \mathrm{~h}$ of hypoxia, the induction of gcCited $3 b$ expression was detected in the brain, gill, heart, and kidney.

In all replicates of each hypoxic tissue, the mRNA expression level of gcCited $3 a$ and gcCited $3 b$ was normalized against the $28 \mathrm{~S}$ rRNA and compared to their normoxic counterparts. If the expression level following hypoxia was equal to the normoxia control group, the hypoxia:normoxia expression ratio should be equal to one. In contrast, this ratio is expected to be significantly greater than one in the case of hypoxic induction of the genes. The $4 \mathrm{~h}$ and $96 \mathrm{~h}$ datasets for each tissue were combined and a non-parametric $\chi^{2}$ test was performed to examine the significance of the induction. The analysis indicated that the expression of both gcCited $3 a$ and $g c$ Cited $3 b$ was significantly different in the kidney and 
Table I: Deduced CITEDI and CITED3 proteins for phylogenetic analysis.

\begin{tabular}{|c|c|c|}
\hline Abbreviations & Standings & Accession numbers \\
\hline olCITED3a & Oryzias latipes CITED3a & scaffold 164\# \\
\hline omCITED3a & Oryzias melastigma CITED3a & [GenBank: ACA52075] \\
\hline fCITED3a & Fugu CITED3a & scaffold $2627^{*}$ \\
\hline gcCITED3a & grass carp CITED3a & [GenBank: AAO48505] \\
\hline zCITED3a & zebrafish CITED3a & [GenBank: AAK437/5] \\
\hline fCITED3b & Fugu CITED3b & scaffold $301 *$ \\
\hline olCITED3b & O. latipes CITED3b & scaffold 8\# \\
\hline omCITED3b & O. melastigma CITED3b & [GenBank: ACA52076] \\
\hline gcClTED3b & grass carp CITED3b & [GenBank: ACA48500] \\
\hline zCITED3b & zebrafish CITED3b & [GenBank: XP 695901] \\
\hline chCITED3 & chicken CITED3 & [GenBank: AAF76|48] \\
\hline xICITED3 & Xenopus CITED3 & [GenBank: $\mathrm{BCl064I5]}$ \\
\hline gcCITEDI & grass carp CITEDI & [GenBank: ACA4850I] \\
\hline zCITEDI & zebrafish CITEDI & [GenBank: ACA02700] \\
\hline fCITEDI & Fugu CITEDI & [GenBank: CAF90007] \\
\hline olCITEDI & O. latipes CITEDI & scaffold 204\# \\
\hline omCITEDI & O. melastigma CITEDI & [GenBank: ACA52074] \\
\hline
\end{tabular}

\# CITED proteins deduced from the Japanese medaka genome database

* CITED proteins deduced from the Fugu genome database (JGI Fugu genome v3.0)

The abbreviations are listed from top to bottom in accordance with Figure 2.
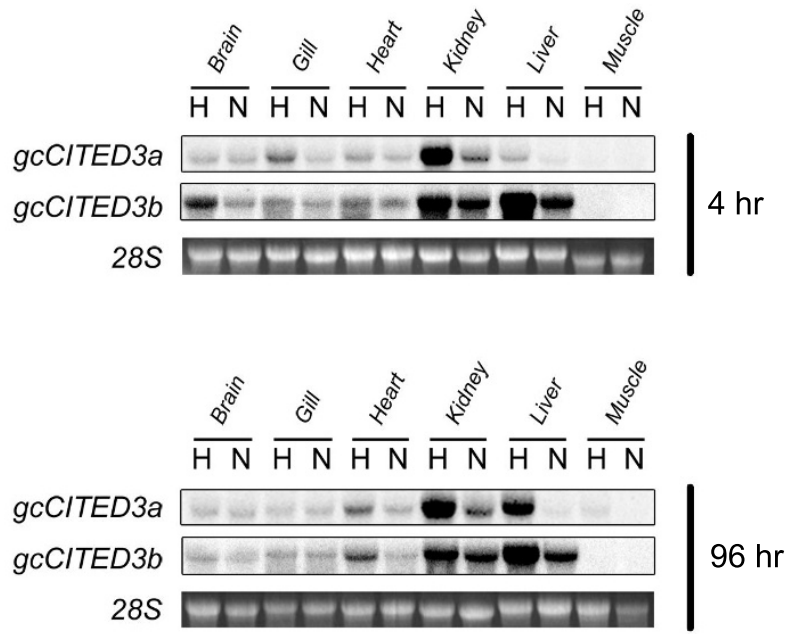

Figure 3

Northern blot analysis of gcCited3a and gcCited $3 b$. Fish tissues (brain, gill, heart, kidney, liver, and muscle) were isolated from normoxic $(N)$ and hypoxic $(H)$ grass carp following $4 \mathrm{~h}$ and $96 \mathrm{~h}$ of exposure as indicated. Total RNA from each tissue was isolated and analyzed by Northern hybridization using gene-specific probes for gCCITED3a and gcCITED 3b. Ethidium bromide-stained 28S rRNA is shown as the loading control. A representative Northern blot derived from the tissues of one normoxic and one hypoxic fish (from a total of three in each group) is shown here. liver following hypoxia compared to the normoxic controls $(p<0.05)$.

\section{Activation of gcCited3a and gcCited3b promoter activity by gcHIF-I in CHO cells}

To investigate whether gcHIF-1 regulates the gcCited $3 a$ and $g c$ Cited $3 b$ gene promoters, Chinese hamster ovary (CHO) cells were transiently transfected with the pCITED3a $(-1817 /+30)$ or pCITED3b $(-1713 /+76)$ luciferase construct, together with pBK-CMV-gcHIF1 $\alpha$ [23], or the empty pBK-CMV expression vector. As shown in Figure 4, luciferase activity was strongly activated in $\mathrm{CHO}$ cells co-transfected with pCITED3a $(-1826 /+30)$ and the pBK-CMV-gcHIF-1 $\alpha$ (ca. 3.2-fold), while cells similarly transfected with pCITED3b(-1731/+76) exhibited an even greater HIF-1-induction (ca. 15-fold), when compared to control cells transfected with the empty pGL3-Basic vector $(p<0.05)$. Interestingly, promoter sequence analysis revealed the presence of a single core HRE (CGTG) at position -59/-56 of the 5'-flanking region of the gcCited $3 a$ gene (Figure 5A), while two putative HREs in the reverse DNA strand (CACG) were detected at $-629 /-626$ and $-510 /-507$ of the gcCited $3 b$ gene (Figure $5 \mathrm{~B}$ ).

At the time of the study, no functional HRE had been reported in fish, and the binding of the HIF-1 transcription factor to consensus and non-consensus HREs had only been speculated [24]. In order to determine whether the gcHIF1 binds to the gcCited $3 a$ and gcCited $3 b$ promoters in vivo, ChIP assays were performed on grass carp kid- 


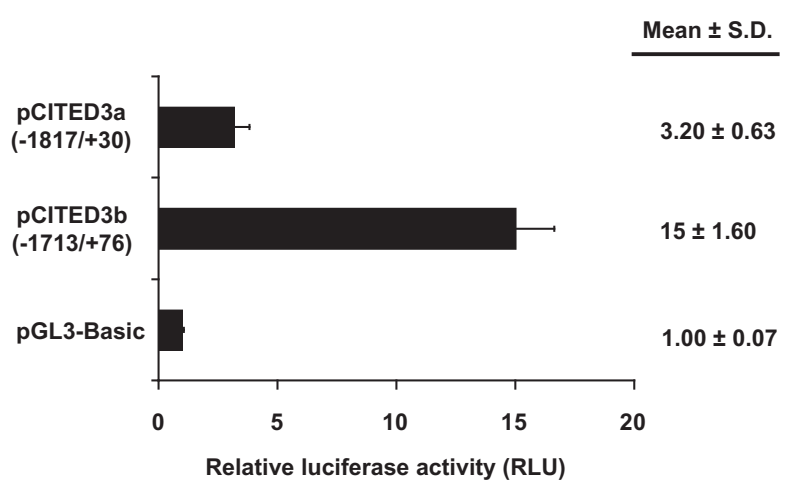

\section{Figure 4}

Transcriptional activation of gcCited $3 a$ and gcCited3b gene promoters and identification of gcHIF-I binding sites by ChIP-PCR. CHO cells were transiently transfected with the PCITED3a(-I8I7/+30), pCITED3b(-I7I3/

$+76)$ or PGL3-Basic luciferase vectors together with PCMVgcHIFI $\alpha$, pCMV-gcARNT2b (HIF-I complex) and pSV $\beta$-gal plasmid or the empty PCMV vector. Luciferase was normalized against $\beta$-gal activity and data represent the means \pm S.D. of three independent experiments. Asterisks indicate significant differences, $P \leq 0.05$, between $P C I T E D 3 a$ and $\mathrm{PCITED} 3 \mathrm{~b}$ promoter constructs and the $\mathrm{PGL3}-$ Basic vector.

ney and liver tissues using PCR primer sets that spanned four overlapping regions (ca. $500 \mathrm{bp}$ each) within the 5'flanking sequences of the gcCited $3 a$ and gcCited $3 b$ genes. Under normoxic conditions, gcHIF-1 did not bind to the gcCited3a promoter; however gcHIF-1 binding was detected in region 4 (nucleotide position $-616 /+30$ ) of the gcCited $3 a$ promoter (which contains a single core HRE at -59/-56) in kidney and liver tissues of fish exposed to $4 \mathrm{~h}$ of hypoxia (Figure 5A). These data demonstrate that gcHIF-1 formed a specific complex at the gcCited3a promoter in vivo. In contrast, three different gcHIF-1 binding patterns were observed at the gcCited $3 b$ promoter following ChIP: specific gcHIF-1 binding was detected at nucleotide positions -1731/-1136 (region 1) and -1257/-742 (region 2), neither of which contain a consensus or core HRE sequence, in the kidney of hypoxic fish, but not in normoxic kidney (Figure 5B). Additionally, gcHIF-1 binding was detected in region 2 of gcCited $3 b$ in the liver of both normoxic and hypoxic fish. Finally, gcHIF-1 binding was specifically detected at nucleotide position $-760 /-283$ (region 3, which contains two core HRE motifs in the reverse orientation) in the liver of hypoxic fish.

\section{Inhibition of gcHIF-I transactivation of HRE-luciferase activity by gcCITED $3 a$ and gcCITED 3 b}

Previous work has demonstrated that the human CITED2 and CITED4 proteins are capable of competing with HIF-
1 for specific binding to the $\mathrm{CH} 1$ domain of $\mathrm{CBP} / \mathrm{p} 300$ and repressing the transcription of HIF-1 regulated genes $[11,14]$. To test whether gcCITED3a and gcCITED3b could also inhibit the transactivation activity of gcHIF-1, $\mathrm{CHO}$ cells were co-transfected with pBK-CMV-gcHIF1 $\alpha$ and pBK-CMV-gcARNT2b, with or without pCMVgcCITED3a or pCMV-gcCITED3b, together with the luciferase reporter construct pSV40-EpoHRE-Luc, which contains four copies of the HRE from the human EPO gene [25]. As shown in Figure 6, the gcHIF-1-mediated transactivation of HRE-luciferase activity in $\mathrm{CHO}$ cells was reduced significantly (ca. $-40 \%$ ) in the presence of gcCITED3a or gcCITED $3 b(p<0.05)$. The CR2 domains of CITED2 and CITED4 have been shown to be involved in the inhibition of HIF-1 transcriptional activity in humans $[11,26]$. To determine whether the CR2 domain of gcCITED3a/gcCITED3b is required for the inhibition of gcHIF-1 activity, CHO cells were transfected with pBKCMV-gcHIF1 $\alpha$ and pBK-CMV-gcARNT2b, together with pCMV-gcCITED3a $\Delta$ CR2 or pCMV-gcCITED $3 b \Delta C R 2$ (deletion mutants lacking the CR2 domain) expression vectors. No significant reduction in gcHIF-1 transactivation of HRE-luciferase activity was observed in the presence of either of these two CR2-deletion derivatives (Figure 6), indicating that the negative regulatory effect of gcCITED3a and gcCITED3b on gcHIF-1 is dependent upon the CR2 domain of these proteins. Next, to determine whether the inhibition of the gcHIF-1-mediated transactivation of HRE-luciferase activity may be due to reduced synthesis of gcHIF- $1 \alpha$ caused by ectopic expression of gcCITED3a or gcCITED3b, Western blot analysis was performed using an anti-gcHIF- $1 \alpha$ antibody [23]. $\mathrm{CHO}$ cells transfected with pBK-CMV-gcHIF- $1 \alpha$ alone or co-transfected with pCMV-gcCITED3a or pCMVgcCITED3b contained comparable levels of the gcHIF- $1 \alpha$ protein (data not shown), which indicated that the decrease in gcHIF-1 transcriptional activity in the presence of gcCITED3a/gcCITED3b is not due to reduced gcHIF-1 synthesis.

\section{gcCITED3a and gcCITED3b physically interact with CBPI p300}

Since gcCITED3a and gcCITED3b have been shown to repress the transcriptional activity of gcHIF-1 (presumably via competition for the $\mathrm{CBP} / \mathrm{p} 300$ co-transactivator), we used immunoprecipitation and GST pull-down assays to determine whether these proteins can directly interact with $\mathrm{CBP} / \mathrm{p} 300$. CHO cells were transfected with pGFPgcCITED3a, pGFP-CITED3b, pGFP-gcCITED3a $\triangle$ CR2 or pGFP-CITED $3 b \Delta C R 2$, and whole cell lysates were prepared and immunoprecipitated with an anti-CBP antibody (Santa Cruz). Western blot analysis of the anti-CBP immunoprecipitates using an anti-GFP antibody (Santa Cruz) (Figure 7A) demonstrated that both gcCITED3a and gcCITED3b co-immunoprecipitate with the endogenous 

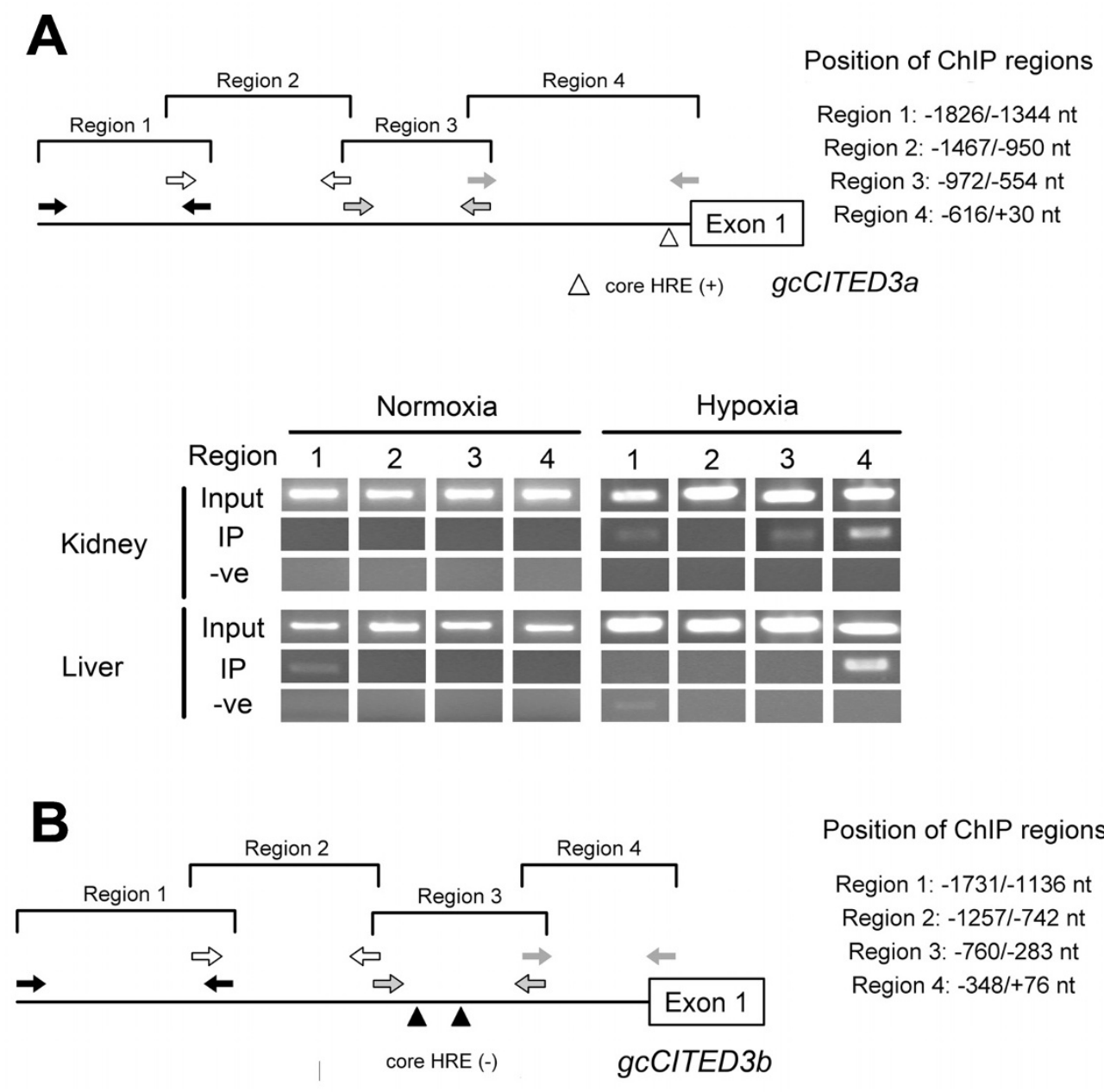

\author{
Position of ChIP regions \\ Region 1: -1731/-1136 nt \\ Region 2: $-1257 /-742 \mathrm{nt}$ \\ Region 3: $-760 /-283 \mathrm{nt}$ \\ Region 4: $-348 /+76 \mathrm{nt}$
}

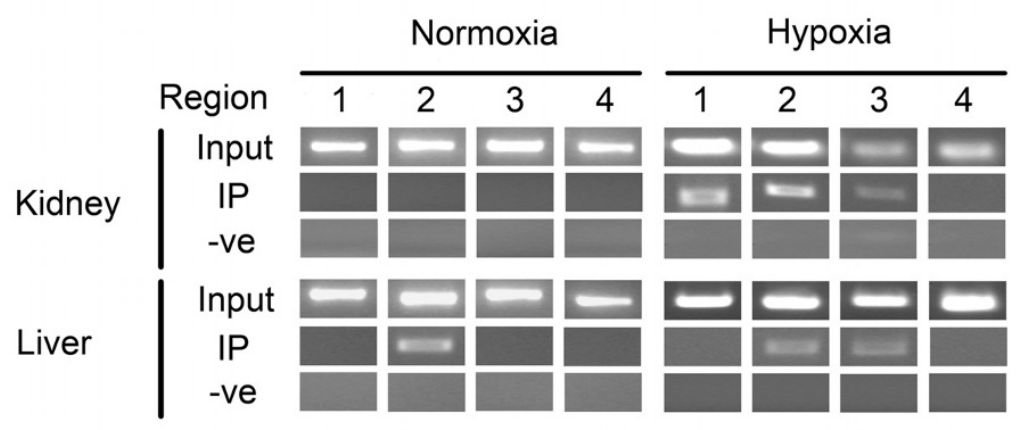

\title{
Figure 5
}

ChIP-PCR analysis of gcHIF-I binding to the gcCited3a and gcCited3b gene promoters. A. The primer-sets (indicated by opposing arrows of the same grey scale) for ChIP-PCR amplification of different regions of the 5 '-flanking sequence of gcCITED $3 a$ are shown, and the regions analyzed are demarcated on the right panel. $B$. The primer-sets (indicated by opposing arrows of the same grey scale) for ChIP-PCR amplification of different regions of the 5 '-flanking sequence of gcCITED3b are shown, and the regions analyzed are demarcated on the right panel. Representative ChIP results from kidney (upper panel) and liver (lower panel) of normoxic (left panel) and hypoxic (right panel) fish. The PCR products of samples without immunoprecipitation (Input), immunoprecipitated with anti-gcHIF-I $\alpha$ anti-serum (IP) and water (-ve) were resolved by gel electrophoresis. A PCR band appears if a DNA region is bound by gcHIF-I in the IP (immunoprecipitated) samples. 


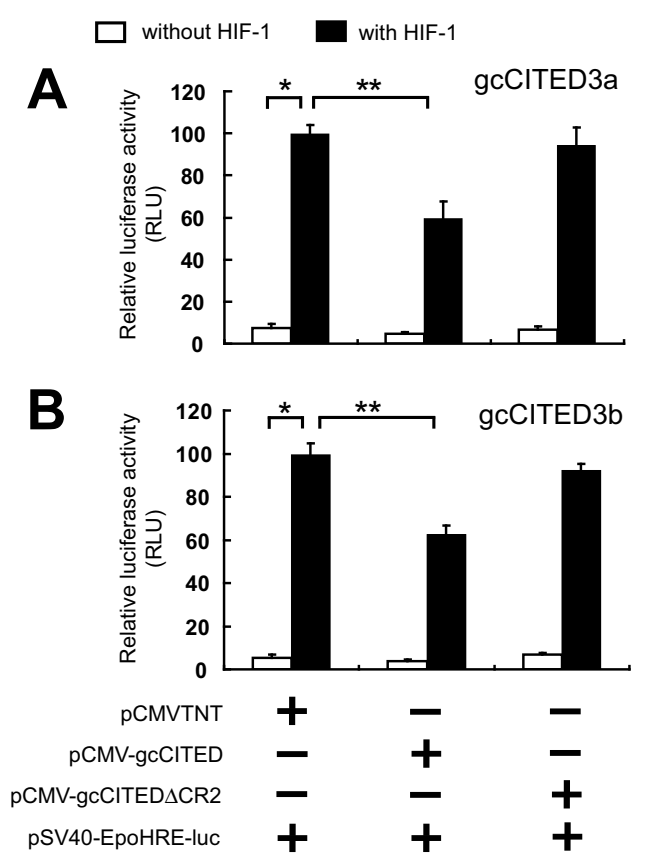

\section{Figure 6}

Transactivation of HRE-luciferase activity by gcHIF-I is inhibited by gcCITED $3 a$ and gcCITED $3 b$. CHO cells were co-transfected with a PSV40-EpoHRE-luciferase reporter and $\mathrm{PSV}$ - $\beta$-gal vector (control for transfection efficiency) along with $\mathrm{pBK}-\mathrm{CMV}$-gcHIF- $\mathrm{I} \alpha$ and $\mathrm{pBK}-\mathrm{CMV}$ gcARNT2b or empty pCMV-TNT vector. Wild-type pCMVgcCITED3a or deletion mutant plasmid PCMV-

gcCITED3a $\triangle$ CR2 (panel A); or PCMV-gcCITED3b or deletion mutant plasmid pCMV-gcCITED3b $\triangle C R 2$ (panel B) was also co-transfected with pBK-CMV-gcHIF-I $\alpha$. Relative luciferase activity is the ratio of luciferase over $\beta$-galactosidase activity. Transfections were performed in triplicates and data are expressed as means \pm S.D. of three independent experiments. Single asterisks $(*)$ indicate significant differences between $\mathrm{CHO}$ cells co-transfected with (filled bars) or without (open bars) gcHIF-I in the absence of gcCITED, $p<0.05$; double asterisks $(* *)$ indicate significant differences in luciferase activities of $\mathrm{CHO}$ cells co-transfected with PCMVgcCITED or PCMV-gcClTED $\triangle C R 2$ in the presence of gcHIFI, $p<0.05$.

$\mathrm{CBP} / \mathrm{p} 300$ proteins in the $\mathrm{CHO}$ cells. This result suggests that both proteins are capable of physically interacting with $\mathrm{CBP} / \mathrm{p} 300$. Since the interaction of human CITED2 and CITED4 with $\mathrm{CBP} / \mathrm{p} 300$ has been shown to be dependent on the CR2 domain $[11,26]$, we deleted this domain in gcCITED3a and gcCITED3b. Interestingly, coimmunoprecipitation was also observed between the mutant GFP-gcCITED3a $\Delta$ CR2 and GFP-gcCITED $3 b \Delta C R 2$ proteins and $\mathrm{CBP} / \mathrm{p} 300$, while GFP alone did not show any interaction. Taken together, these results indicate that,

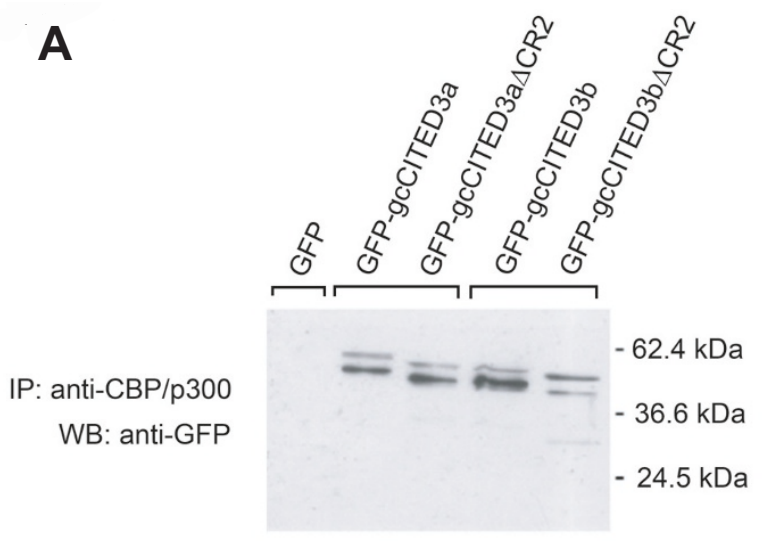

B

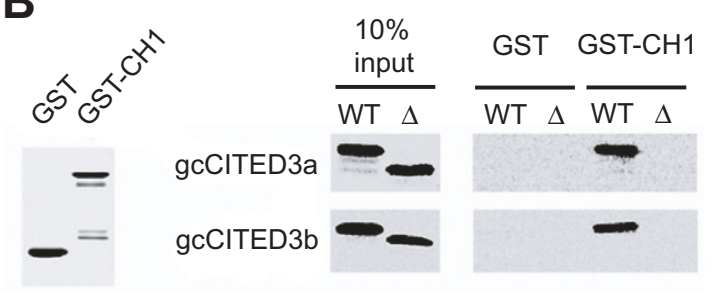

\section{Figure 7}

gCCITED $3 a$ and gcCITED $3 b$ physically interact with CBP/p300. A. Immunoprecipitation and Western blot analysis. $\mathrm{CHO}$ cells were separately transfected with pGFPgcCITED3a, pGFP-gcCITED3a $\triangle$ CR2, pGFP-CITED3b, or PGFP-CITED $3 b \triangle C R 2$, and whole cell lysates prepared and immunoprecipitated with anti-CBP antibody (Santa Cruz). The immunoprecipitates were resolved on $12 \%$ denaturing SDS-PAGE and Western blot analysis was carried out to detect GFP fusion proteins using anti-GFP antibody (Santa Cruz). B. GST pull-down assays. GST protein only or GST protein fused to gc-p300/CHI (CHI domain of grass carp p300) was purified from bacterial culture and immobilized on glutathione-Sepharose beads. In-vitro-transcribed and -translated [35S]-methionine-labeled gcCITED3 or gcCITED3 $\Delta$ CR2 was incubated with purified GST-fused CHI or GST alone as indicated in the figure.

unlike hCITED2 and hCITED4, the CR2 domain in gcCITED3a and gcCITED3b is not required for physical interaction of the proteins with $\mathrm{CBP} / \mathrm{p} 300$.

Using GST-pull down assays, we next determined whether gcCITED3a and gcCITED3b physically bind to the $\mathrm{CH} 1$ domain of the grass carp p300 protein. The $\mathrm{CH} 1$ domain of grass carp p300 (gc-p300/CH1) [GenBank: EU450671] was amplified using degenerate primers and subcloned into the pGEX-5X-2 vector (Promega). GST and GST-gcp300/CH1 fusion proteins were incubated with in-vitrotranscribed and -translated [ $\left.{ }^{35} \mathrm{~S}\right]$ methionine-labeled gcCITED proteins, followed by fractionation on SDSPAGE. As shown in Figure $7 \mathrm{~B}$, only the wild-type 
gcCITED3a and gcCITED3b proteins, but not the gcCITED3a $\triangle \mathrm{CR} 2$ or gcCITED3b $\triangle \mathrm{CR} 2$ deletion derivatives, were pulled down by the GST-gc-p300/CH1 fusion protein, demonstrating that the CR2 domain facilitates specific binding of both gcCITED3a and gcCITED3b to the $\mathrm{CH} 1$ domain of $\mathrm{CBP} / \mathrm{p} 300$.

\section{Discussion}

CITED3 is the least studied member of the CITED family, and the molecular targets and specific mechanisms underlying the action of CITED3 have not yet been clearly identified. In this study, we have characterized two closelyrelated CITED3 genes - gcCited $3 a$ and gcCited $3 b$ - in the hypoxia-tolerant grass carp, and in silico analyses demonstrated that these two CITED homologs are present only in the genomes of fish and are absent in mammals. Whilst we were able to recently identify CITED2 cDNAs from zebrafish and grass carp (unpublished observations), bioinformatic searches of all available fish genomes with various mammalian CITED4 proteins failed to turn up any CITED4-like sequences, which suggested that Cited4 genes are likely absent in fish. Interestingly, parsimony analysis of CITED proteins from diverse animal species has previously indicated that fish CITED3 proteins are most closely related to the mammalian CITED4 [20]. This raises the possibility that CITED3 and CITED4 are likely orthologous proteins that may have arisen subsequent to lineage divergence between mammalian and non-mammalian vertebrates, and that CITED3a and CITED3b have descended from a gene duplication event in fish from an ancestral CITED3 gene.

We have shown that the gcCited $3 a$ and $g c$ Cited $3 b$ genes are transcriptionally up-regulated by the gcHIF-1 transcription factor (Figure 4), and the gene products, in turn, repress gcHIF-1 transcriptional activity at the molecular level (Figure 6). As gcCited $3 a$ and gcCited $3 b$ are differentially activated transcriptionally by hypoxia in certain fish tissues (Figure 3), our results suggest that gcCITED3a/ gcCITED3b may serve to auto-regulate the HIF transcriptional response in hypoxic cells of the corresponding tissues. Interestingly, gene transfection studies demonstrated that gcHIF-1 transcriptional activity was inhibited by ectopic expression of the wild-type gcCITED3a/gcCITED3b, but not the mutant gcCITED $3 a \triangle C R 2$ or gcCITED $3 b \Delta C R 2$ proteins, which provided compelling evidence that the observed inhibition of HIF-1 activity is mediated by the CR2 domains of gcCITED3a and gcCITED3b. While GST pull-down assays demonstrated that the CR2 domains of gcCITED3a and gcCITED $3 b$ are indeed required for specific binding of the proteins to the $\mathrm{CH} 1$ domain of the $\mathrm{CBP} / \mathrm{p} 300$ co-transactivator (Figure 7B), co-immunoprecipitation experiments showed that gcCITED3a, gcCITED3b, and the corresponding $\triangle \mathrm{CR} 2$ mutant proteins could all physically interact with the endogenous $\mathrm{CBP} / \mathrm{p} 300$ in $\mathrm{CHO}$ cells (Figure 7A). These results are consistent with the notion that both gcCITED3a and gcCITED3b can physically interact with $\mathrm{CBP} / \mathrm{p} 300$ at multiple sites apart from the respective CR2 and $\mathrm{CH} 1$ domains of these proteins, and the functional implications of which await further investigations. To our knowledge, this is the first study demonstrating physical interaction of CITED3 proteins with p300, and that CITED3 can negatively regulate HIF-1 transcriptional activity in a manner similar to the mammalian CITED2 and CITED4 proteins $[11,27]$, which require their CR2 domains to exert this function.

In vivo regulation of the gcCited $3 a$ and gcCited $3 b$ genes by HIF-1 in the kidney and liver tissues of hypoxic fish was confirmed by ChIP-PCR assays, which revealed that endogenous gcHIF- $1 \alpha$ is recruited to the gcCited $3 a$ promoter at region 4 (which contains a single core HRE at 59/-56) (Figure 5A). In contrast, three different ChIP patterns were observed with the gcCited $3 b$ promoter. Most notably, gcHIF-1 binding was detected in gcCited $3 b$ in the kidney of hypoxic fish (but not normoxic kidney) at regions 1 (nt positions $-1731 /-1136$ ) and 2 (nt positions -1257/-742); neither of which contains any consensus HRE sequence (Figure 5B). These observations are not surprising as it has been previously shown that HIF-1 is expressed in many organs in mammals [28] and fish [29], albeit at varying levels, under both normoxic and hypoxic conditions. What was surprising, however, was the binding of gcHIF-1 to two HRE-less regions in gcCited $3 b$. A closer inspection of the ChIP-positive regions of the gcCITED $3 a$ and $g c C I T E D 3 b$ promoters also failed to identify any sequence motifs that resemble the non-canonical HRE sequence (GATGTG) recently reported in killifish [30]. Indeed, the binding of HIFs to gene promoters that lack the consensus HRE motif (NRCGTG) have been reported recently for human HIF-1 and HIF-2 using ChIP [31], whereby the binding of transcription factors to promoter regions lacking the consensus recognition sequence may be attributed to the formation of higher order DNA/ protein complexes [31-33].

Experiments are currently underway in our lab to further explore the selectivity of HIF-1 binding to DNA that lacks the consensus HRE motif, 5'-RCGTG-3'. Notwithstanding, our findings in this study indicate that the gcCited $3 a$ and gcCited $3 b$ genes interact differentially under normoxia and hypoxia with gcHIF-1 in kidney and liver tissues, presumably via different sets of distal enhancer binding proteins to achieve differential gene expression.

Northern blot analysis revealed that both gcCited $3 a$ and gcCited $3 b$ are ubiquitously expressed in all fish tissues examined, except muscle (Figure 3). Although they share a similar overall mRNA expression pattern, the predomi- 
nant expression sites of gcCited $3 a$ and gcCited $3 b$ are the kidney and liver, respectively. This raises the question of whether these two genes have independent or partially redundant functions in these tissues. The major structural difference of these two homologs with other CITED subtypes is the presence of a QH-rich domain in both gcCITED $3 a$ and gcCITED3b, which may contribute to functional differences. In addition to their known involvement in the regulation of HIF-1 signaling, a growing body of evidence indicates that the CITED proteins can interact with a variety of signaling molecules, suggesting that these proteins may have a role in diverse cellular processes. For example, while CITED1 is able to activate Smad4-dependent transcription, it has also been shown to repress the $\mathrm{Wnt} / \beta$-catenin signaling pathway, which regulates early nephronic patterning in vertebrates [34]. CITED2, on the other hand, interacts with Smad2 and Smad3 to induce expression of the matrix metalloproteinase 9 gene in TGF- $\beta$-mediated tumor cell invasion [16]. In addition, CITED2 and CITED4, along with some isoforms of the transcription factor AP2, have been shown to activate genes that may be involved in neural crest, neural tube, and cardiac development [14,35]. Moreover, CITED1 and CITED2 were shown to interact with ER- $\alpha$ and PPAR- $\alpha$, respectively, to activate the transcription of target genes $[7,15]$. Overall, based on the phenotypes of their gene knockouts and their interactions with many different and important developmental signaling pathways, it appears that members of the CITED family are versatile transcriptional cofactors or effector molecules. These genes likely engage in diverse cellular and developmental processes/functions and serve to fine-tune a number of signaling pathways to mediate their ultimate biological functions.

All known interactions between CITED proteins and various other transcription factors are bridged by the common transcriptional cofactor $\mathrm{CBP} / \mathrm{p} 300$. This cofactor is required to mediate either the transcriptional gene activation or repression mechanisms of the CITED proteins. During gene activation, CITED proteins interact with $\mathrm{CBP} / \mathrm{p} 300$ via the CR2 domain to form a transcription complex along with other transcription factors, such as Smad3, Smad4, or AP2A, B, or C [14,16,35-37]. This complex induces the transcription of specific target genes. Conversely, during gene repression, CITED proteins may compete with specific transcription factors, such as HIF$1 \alpha$ or $\beta$-catenin $[11,26,34]$, for a common binding site on the CBP/p300 protein. This binding diminishes the transactivation activity of the latter transcription factors. Based on the studies of mammalian CITED genes, with which the grass carp CITED proteins share significant sequence homology (in particular the CR2 domain), and the ability to bind $\mathrm{CBP} / \mathrm{p} 300$, it is likely that the gcCITED proteins may interact with the equivalent transcription factors described in mammalian systems to regulate similar cellular processes in fish.

Both the gcCited $3 a$ and gcCited $3 b$ genes can be transactivated by subjecting fish to both short- and long-term exposure to low oxygen tension. Long-term exposure led to a dramatic over-expression of both gcCited $3 a$ and gcCited $3 b$ in specific tissues, suggesting that certain processes in these tissues require gcCITED3a or gcCITED3b or that the CITED3a or CITED3b proteins directly alleviate the effect of hypoxia. The gene responses to hypoxia by other members of the CITED family, and their roles in development, indicate that these proteins may be responsible for controlling gene transcription during tissue development, which may be driven by slight hypoxia in the developing tissues [38].

\section{Conclusion}

Taken together, gcCITED $3 a$ and gcCITED $3 b$ genes are differentially expressed and regulated in different fish organs in response to hypoxic stress. Both genes are activated by gcHIF-1 in gene transfection studies, and ChIP assays comparing normal and hypoxic conditions reveal differential in vivo binding of gcHIF-1 to both gene promoters in kidney and liver tissues. HRE-luciferase reporter assays showed that both gcCITED3a and gcCITED3b proteins inhibit gcHIF-1 transcriptional activity, presumably by binding specifically to the $\mathrm{CH} 1$ domain of the grass carp p300 protein as confirmed by GST pull-down assays.

\section{Methods}

\section{Fish Culture and Treatment}

Animal care and experimentation were undertaken in accordance with City University of Hong Kong animal care guidelines. Grass carp (Ctenopharyngodon idella) of ca. $500 \mathrm{~g}$ body weight were obtained from a fish hatchery in Panyu, Guangdong, China and maintained in 300-l fiberglass tanks with circulating, filtered and well-aerated water at $20 \pm 1^{\circ} \mathrm{C}$ under a $12: 12 \mathrm{~h}$ day:night cycle. Fishes were reared under normoxia $\left(7.0 \pm 0.2 \mathrm{mg} \mathrm{O}_{2} / \mathrm{l}\right)$ or hypoxia $\left(0.5 \pm 0.3 \mathrm{mg} \mathrm{O}_{2} / \mathrm{l}\right)$ for 4 and $96 \mathrm{~h}$ in a continuous flow system as previously described [39]. Dissolved oxygen (DO) was monitored continuously using a YSI Model 580 dissolved oxygen meter (Geo Scientific Inc., Canada). After the exposure period, the fishes were anaesthetized and tissues were immediately dissected out, snap-frozen in liquid nitrogen and stored at $-80^{\circ} \mathrm{C}$ until ready to be processed.

\section{RNA Isolation and Cloning of Full-length cDNAs}

Total RNA was isolated using the TRIZOL reagent (Invitrogen, USA) according to the manufacturer's instructions. Poly(A)+ RNA was isolated from total RNA using the PolyATtract mRNA Isolation System III kit (Promega, USA) according to the manufacturer's instructions. Cloning of 
the full-length gcCITED3a cDNA sequence has been previously reported by our group [20]. To facilitate cloning of the full-length gcCITED3b cDNA, 5'- and 3'-RACE PCR were performed using the Marathon Amplification Kit (Clontech, USA). Briefly, first-strand cDNA was synthesized from $1 \mu \mathrm{g}$ kidney poly(A)+ RNA of hypoxic fish using the cDNA Synthesis Primer and AMV reverse transcriptase. Second-strand cDNA was generated in an enzymatic reaction containing DNA polymerase I, DNA ligase, and RNase H from E.coli. Double-stranded cDNA was bluntended with T4 DNA polymerase and ligated to Marathon cDNA Adaptor. For 5'-RACE, adaptor-ligated ds-cDNA was used as the template in PCR amplification using adaptor primer AP1 and antisense gene-specific primer 5' GSP1 (5'-CCACCACTTATCTGGCCGTTGACCT-3'), derived from the partial gcCITED3b cDNA sequence. Nested PCR was performed using nested adaptor primer $\mathrm{AP} 2$, and gene-specific primer 5' GSP2 (5'-ACGCCATTCATCACGTTCCTCTGCC-3'). For 3'-RACE, PCR amplification of the ds-cDNA was performed with primer AP1 and gene-specific primer 3' GSP1 (5'-CCTTACAGCATCTCAGCAGCTTATGGC-3'). Nested PCR was performed with AP2 and gene-specific primer 3' GSP2 (5'-CACAGAATGGGTCCTGCTCAGTTGG-3'). The full-length gcCITED3b cDNA was cloned by RT-PCR using forward and reverse primers targeting the 5'- and 3'-RACE products, respectively, with $P f u$ DNA polymerase (Promega). The PCR profile consisted of: denaturation at $95^{\circ} \mathrm{C}$ for 2 min followed by 30 cycles of $95^{\circ} \mathrm{C}$ for $1 \mathrm{~min}, 60^{\circ} \mathrm{C}$ for $30 \mathrm{~s}$ and $73^{\circ} \mathrm{C}$ for $3 \mathrm{~min}$; and a final extension step at $73^{\circ} \mathrm{C}$ for $5 \mathrm{~min}$. The full-length cDNA was confirmed by DNA sequencing.

\section{Preparation of Reporter Constructs and Expression Vectors}

The 5'-flanking sequences of gcCited $3 a$ and gcCited $3 b$ were obtained using the GenomeWalker Universal Kit (Clontech) according to the manufacturer's instructions. Briefly, $2.5 \mu$ grass carp genomic DNA was digested separately with the restriction enzymes DraI, EcoRV, PvuII or StuI. GenomeWalker Adaptor was ligated to the purified DNA and ligation products were subjected to two rounds of PCR (primary and secondary PCR) using the Advantage Genomic Polymerase Mix (Clontech). The touch-down PCR profiles for primary and secondary PCR consisted of denaturation at $94^{\circ} \mathrm{C}$ for 2 min followed by 5 cycles of denaturation at $94^{\circ} \mathrm{C}$ for $30 \mathrm{~s}$ and annealing at $68^{\circ} \mathrm{C}$ for $30 \mathrm{~s}$, and 25 cycles of annealing at $65^{\circ} \mathrm{C}$ for $30 \mathrm{~s}$ and extension at $68^{\circ} \mathrm{C}$ for $3 \mathrm{~min}$. This is followed by a final extension at $68^{\circ} \mathrm{C}$ for $5 \mathrm{~min}$. Primers CITED3a-F (5'GTGTCTCAATCTAGTGAGCTGCCTACC-3') or CITED3bF (5'-CAGTTGAAGCTCTGCGTAGCAATACTGTTC-3') and AP1 were used in primary PCR, while primers CITED3a-R (5'-CGGCAGGACAATTGAGCTTTATCTGTTC-3') or CITED3b-R (5'-GGTCCAGCCTTCTCGTTATCACAGCT-3') and AP2 were used in the secondary PCR.
Amplification products were purified and cloned into plasmid vectors for DNA sequencing. The gcCITED3a (1817 bp) and gcCITED3b (1713 bp) constructs used in this study were cloned into the promoterless pGL3-Basic luciferase reporter plasmid (Promega). Vectors expressing the grass carp HIF-1 $\alpha$ (pBK-CMV-gcHIF-1 $\alpha)$ and ARNT2b (pBK-CMV-gcARNT2b) were constructed as previously described [23]. Coding sequences for gcCITED3a, gcCITED $3 b$, the gcCITED $3 a \triangle C R 2$ and gcCITED $3 b \Delta C R 2$ deletion derivatives were amplified by PCR and subcloned into the pCMV-TNT expression vector (Promega) using standard procedures. The coding sequence of the $\mathrm{CH} 1$ domain of the grass carp p300 protein was PCRamplified using gene-specific primers gcp3GST-F (5'GAGTATCGAATTCCTCAGCATGGGCAG-3'; XhoI site is underlined) and gcp3GST-R (5'-TATCTCGAGTCACAGCATTCCCGGATG-3'; EcoRI site is underlined), and the PCR product was subcloned into the Xhol/EcoRI sites of the pGEX-5X-2 GST vector (GE Healthcare, USA) to yield pGST-gcCH1. GFP-tagged gcCITED3a, gcCITED3b, gcCITED $3 a \Delta C R 2$ and gcCITED $3 \mathrm{~b} \Delta \mathrm{CR} 2$ proteins were produced by subcloning the ORF of the corresponding cDNAs into the pCMV-GFP expression vector (Stratagene, USA).

\section{Northern Hybridization Analysis}

Total RNA $(13.5 \mu \mathrm{g})$ was electrophoresed on $1 \%(\mathrm{w} / \mathrm{v})$ agarose/formaldehyde gel in $1 \times$ MOPS buffer $(20 \mathrm{mM}$ MOPS, pH 7.0, $5 \mathrm{mM}$ sodium acetate, $1 \mathrm{mM}$ EDTA) and blotted onto Hybond-XL membrane (GE Healthcare). Blots were prehybridized at $65^{\circ} \mathrm{C}$ for $30 \mathrm{~min}$ in ExpressHyb solution (Clontech) and Northern hybridization carried out at $65^{\circ} \mathrm{C}$ for $2 \mathrm{~h}$ in the same solution containing $2.0 \times 10^{6} \mathrm{cpm} / \mathrm{ml}$ of [32P]dCTP-labeled cDNA probe prepared by random priming (GE Healthcare). Blots were washed thrice in $2 \times$ standard sodium citrate (SSC), $0.05 \%(\mathrm{w} / \mathrm{v})$ sodium dodecyl sulphate (SDS) for $10 \mathrm{~min}$ at room temperature, and twice in $0.1 \times$ SSC, $0.1 \%$ SDS (w/v) for $20 \mathrm{~min}$ at $50^{\circ} \mathrm{C}$. Blots were exposed on a phosphor screen (Kodak, USA) at room temperature for $20 \mathrm{~h}$, and the signals were captured and quantified using the Molecular Imager FX System (Bio-Rad, USA). A 115bp 28S rDNA fragment (and confirmed by DNA sequencing) was amplified from grass carp total DNA using primers 28S-F (5'-GATCCTTCGATGTCGGCTCT-3') and 28S-R (5'-CTAACCTGTCTCACGACGGT-3') and used as an internal control probe in Northern hybridization for normalization of gene expression.

\section{Transient Transfection and Luciferase Reporter Assays}

$\mathrm{CHO}$ cells (kind gift from Professor Peter Ratcliffe of the Wellcome Trust Center for Human Genetics, Oxford University, UK) were seeded in 24 -well plates at $1 \times 10^{5}$ cells per well and transfected with $120 \mathrm{ng}$ of $\mathrm{p}(\mathrm{HRE})_{4}$-Luc reporter plasmid and $60 \mathrm{ng}$ of $\mathrm{pSV} \beta$-Gal expression vector 
(Promega) using LipofectAMINE $2000^{\circledR}$ transfection reagent (Invitrogen) in OptiMEM ${ }^{\circledast}$ I reduced serum medium according to the manufacturer's recommendations. The $\mathrm{p}$ (HRE $)_{4}$-Luc reporter plasmid consists of 4 copies of the human erythropoietin hypoxia-responsive element (HRE) linked to the SV40 promoter and firefly luciferase gene (a gift from Professor Yoshiaki Fujii-Kuriyama, the Center for Tsukuba Advanced Research Alliance and the Institute of Basic Medical Sciences, University of Tsukuba, Japan). Ectopic expression of gcHIF $\alpha$ involved cotransfection of $120 \mathrm{ng}$ of pBK-CMV-gcHIF- $1 \alpha$ or an equimolar amount of the empty $\mathrm{pBK}-\mathrm{CMV}$ vector with the luciferase and $\beta$-Gal reporter plasmids in the presence of $120 \mathrm{ng}$ of pBK-CMV-gcARNT2b. The total DNA used in each transfection was adjusted to $1 \mu \mathrm{g}$ by adding appropriate amount of pcDNA3 vector. Approximately $24 \mathrm{~h}$ posttransfection, cells were harvested and luciferase activity was measured using the Bright-Glo ${ }^{\mathrm{TM}}$ Luciferase assay kit (Promega) and normalized to $\beta$-galactosidase activity to correct for variations in transfection efficiency. The relative luciferase activity of the pGL3-Basic vector was set at 1.0 RLU for each data set. Data are expressed as means \pm S.D. from three independent experiments with three replicates per sample in each experiment.

\section{Co-immunoprecipitation Assay}

CHO cells $\left(1 \times 10^{6}\right)$ were transfected with $10 \mu \mathrm{g}$ of pCMVGFP or pCMV-GFP-gcCITED3a, pCMV-GFP-gcCITED3b, pCMV-GFP-gcCITED3a $\triangle \mathrm{CR} 2$ or pCMV-GFPgcCITED $3 \mathrm{~b} \Delta \mathrm{CR} 2$. Twenty hours post-transfection, the cells were washed in ice-cold $1 \times$ PBS buffer and lysed in $0.5 \mathrm{ml}$ TNTE buffer at $4^{\circ} \mathrm{C}$. Cell lysate was incubated overnight at $4^{\circ} \mathrm{C}$ with mouse anti-CBP/p300 antibody (Santa Cruz, USA) and then incubated with Protein A/G agarose (Santa Cruz) at $4^{\circ} \mathrm{C}$ for 1 hour. Unbound proteins were removed by washing with TNTE buffer and bound proteins were denatured by boiling in SDS-PAGE buffer followed by Western blot analysis using anti-GFP antibody (diluted 1:5000, B-2, Santa Cruz).

\section{Western Blot Analysis}

GFP-fusion proteins were separated in 12\% SDS-PAGE, transferred to nitrocellulose membrane (Bio-Rad), blocked in $4 \%$ non-fat dry milk in $0.1 \%$ TPBS $(0.1 \%$ Tween 20 in $0.1 \mathrm{M} \mathrm{Na}_{2} \mathrm{HPO}_{4}, 0.1 \mathrm{M} \mathrm{NaH}_{2} \mathrm{PO}_{4}, 0.5 \mathrm{M}$ $\mathrm{NaCl} \mathrm{pH} \mathrm{7.2)} \mathrm{for} 30 \mathrm{~min}$, and the membrane was incubated overnight at $4{ }^{\circ} \mathrm{C}$ with anti-GFP antibody B-2 (diluted 1:5000; Santa Cruz) in the blocking medium. Non-specific binding of antibody was washed off with three changes of $0.1 \%$ TPBS followed by detection with 1:5000 diluted HRP-conjugated secondary anti-mouse IgG (Zymed, USA) at room temperature for $1 \mathrm{~h}$ using the ECL Plus Detection System (GE Healthcare). Western blot detection of gcHIF- $1 \alpha$ and $\beta$-tubulin proteins was carried out as previously described [23].

\section{Glutathione S-transferase (GST)-pull-down Assay}

GST-fusion proteins (or GST alone) were induced in E. coli DH5 $\alpha$ for $30 \mathrm{~min}$ in $10 \mathrm{mM}$ isopropyl- $\beta$-D-thiogalactopyranoside (IPTG). Cells were lysed and GST-fusion proteins were prebound with $30 \mu \mathrm{l}$ of glutathione-Sepharose beads. The beads were incubated with the in-vitro-transcribed and -translated [ $\left.{ }^{35} \mathrm{~S}\right]$ methionine-labeled proteins for $3-4 \mathrm{~h}$ at $4{ }^{\circ} \mathrm{C}$. The beads were washed three times with washing buffer, and analyzed in 15\% SDS-PAGE, and protein bands were visualized using the FX phosphoimaging system (Bio-Rad).

\section{In Vitro Translation}

The pCMV-gcCITED3a, pCMV-gcCITED3b, pCMVgcCITED $3 a \triangle C R 2$ and pCMV-gcCITED3b $\triangle C R 2$ plasmids were transcribed in vitro and translated using the TNT T7 Quick coupled transcription/translation system (Promega) in the presence of [ $\left.{ }^{35} \mathrm{~S}\right]$ methionine according to the manufacturer's instructions. The translated proteins were analyzed in 15\% SDS-PAGE and images visualized using the FX Phosphoimaging system (Bio-Rad).

\section{Chromatin Immunoprecipitation (ChIP) Assay}

Five separate normoxia/hypoxia exposure experiments were carried out, and for each, grass carp (ca. $2.5 \mathrm{~kg}$ each) were acclimatized for one week in normoxic water and then exposed to hypoxia $(n=2)$ or normoxia $(n=2)$ for $4 \mathrm{~h}$. Chromatin immunoprecipitation (ChIP) assay was performed on kidney and liver tissues from these fish according to the instructions of the ChIP assay kit (Upstate, USA). Kidney ( $0.8 \mathrm{~g})$ and liver (1.6 g) tissues were fixed in 1\% formaldehyde (Sigma-Aldrich, USA) at room temperature for $15 \mathrm{~min}$, and the cross-linking reaction was terminated with $125 \mathrm{mM}$ glycine (SigmaAldrich) for $5 \mathrm{~min}$. Tissues were homogenized using a Dounce homogenizer in ice-cold PBS containing $1 \times$ protease inhibitor cocktail (Sigma-Aldrich) and then sonicated six times for $15 \mathrm{~s}$ each in lysis buffer (1\% SDS, 10 $\mathrm{mM}$ EDTA, $50 \mathrm{mM}$ Tris-Cl, $\mathrm{pH} 8.0,1 \times$ protease inhibitor cocktail, and $1 \mathrm{mM}$ PMSF) at 55\% amplitude using a Cole Palmer Ultrasonic Processor to generate DNA fragments of 500 - 800 bp. For immunoprecipitation, a rabbit antigcHIF-1 $\alpha$ polyclonal antibody AB-4 [23] was used. Immunoprecipitated DNA was amplified by PCR using primers spaced 200 - 400 bps apart and encompassing regions that contain putative hypoxia-responsive elements (or HREs) within the gcCited $3 a$ and gcCited $3 b$ gene promoters (Figure 3). For the positive control (input), purified chromatin without the immunoprecipitation step was used for PCR. The PCR profile consisted of 35 cycles of denaturation at $94^{\circ} \mathrm{C}$ for $30 \mathrm{~s}$, annealing at $55^{\circ} \mathrm{C}$ for $45 \mathrm{~s}$, followed by extension at $72^{\circ} \mathrm{C}$ for $1.5 \mathrm{~min}$. PCR was performed in a $25-\mu \mathrm{l}$ reaction mixture containing $5 \mu \mathrm{l}$ of purified DNA, $0.2 \mathrm{mM}$ dNTP, $0.2 \mu \mathrm{M}$ each of forward and reverse primer, $1 \times$ PCR buffer and 0.3 U of Taq DNA polymerase. 


\section{Phylogenetic Analysis}

Phylogenetic analysis was performed by maximum parsimony using the Molecular Evolutionary Genetics Analysis (MEGA) Version 3.1 program http://www.megasoft ware.net/. Evaluation of the inferred phylogeny was performed using the bootstrap test with 1000 replications.

\section{Statistical Analysis}

A non-parametric $\chi^{2}$ test was used to test the null hypothesis that the ratio of hypoxic:normoxic mRNA expression level was not significantly different from 1 [40]. One-way ANOVA was used to examine inhibitory effects of ectopic expression of gcCITED3a and gcCITED3b on gcHIF- $1 \alpha$ induction on HRE-driven luciferase activity. Where significant effects were detected, Tukey's tests were performed to identify significant difference between individual means; $\alpha=0.05$ was used in all statistical tests.

\section{List of abbreviations}

gcCITED: grass carp cAMP-responsive element-binding protein (CBP)/p300-interacting transactivator with glutamic acid/aspartic acid-rich tail; ChIP: chromatin immunoprecipitation; HIF: hypoxia inducible factor; HRE: hypoxia-responsive element; GST: glutathione-Stransferase; CH1: cysteine/histidine-rich domain; CBP: CREB-binding protein.

\section{Authors' contributions}

PKSN designed and carried out most of the experimental work described in this paper. TFNK performed the ChIP experiments, RMKY assisted with many of the expression studies, MMLW contributed to the sequence analysis. SKC and RYCK contributed to the design and planning of this study, and writing of the manuscript. All authors read and approved the final manuscript.

\section{Acknowledgements}

This work was supported by a Central Earmarked Research Grant (Project No. CityUI 27 I/04M) from the Research Grants Council of Hong Kong Special Administrative Region, People's Republic of China.

\section{References}

I. Lisy K, Peet DJ: Turn me on: regulating HIF transcriptional activity. Cell Death and Differentiation 2008, 1 5:642-649.

2. Wang GL, Jiang BH, Rue EA, Semenza GL: Hypoxia-inducible factor $\mathbf{I}$ is a basic-helix-loop-helix-PAS heterodimer regulated by cellular $\mathbf{O}_{2}$ tension. Proc Natl Acad Sci 1995, 92:55 I0-55। 4.

3. Ivan M, Kondo K, Yang H, Kim W, Valiando J, Ohh M, Salic A, Asara JM, Lane WS, Kaelin WG Jr: HIFalpha targeted for VHL-mediated destruction by proline hydroxylation: implications for O2 sensing. Science 200I, 292:464-468.

4. Ohh M, Park C, Ivan M, Hoffman M, Kim T, Huang L, Pavletich N, Chau V, Kaelin WG Jr: Ubiquitination of hypoxia-inducible factor requires direct binding to the beta-domain of the von Hippel-Lindau protein. Nat Cell Biol 2000, 2:423-427.

5. Semenza GL, Nejfelt MK, Chi SM, Antonarakis SE: Hypoxia-inducible nuclear factors bind to an enhancer element located 3' to the human erythropoietin gene. Proc Natl Acad Sci USA 199I, 88:5680-5684.

6. Bamforth SD, Bragança J, Farthing CR, Schneider JE, Broadbent C, Michell AC, Clarke K, Neubauer S, Norris D, Brown NA, Anderson
RH, Bhattacharya S: Cited2 controls left-right patterning and heart development through a Nodal-Pitx2c pathway. Nat Genet 2004, 36: I I89-1 I96.

7. Yahata T, Shao W, Endo H, Hur J, Coser KR, Sun H, Ueda Y, Kato S, Isselbacher K, Brown M, Shioda T: Selective coactivation of estrogen-dependent transcription by CITEDI CBP/p300binding protein. Genes Dev 200I, 15:2598-26I2.

8. Sun HB, Zhu YX, Yin T, Sledge G, Yang YC: MRG I, the product of a melanocyte-specific gene related gene, is a cytokine-inducible transcription factor with transformation activity. Proc Natl Acad Sci USA 1998, 95: I3555-13560.

9. Bhattacharya S, Ratcliffe PJ: ExCITED about HIF. Nat Struct Biol 2003, 10:50I-503.

10. Yokota H, Goldring MB, Sun HB: CITED2-mediated regulation of MMP-I and MMP-I 3 in human chondrocytes under flow shear. J Biol Chem 2003, 278:47275-47280.

II. Bhattacharya S, Michels CL, Leung MK, Arany ZP, Kung AL, Livingston DM: Functional role of $\mathrm{p} 35 \mathrm{srj}$, a novel $\mathrm{p} 300 / \mathrm{CBP}$ binding protein, during transactivation by HIF-I. Genes Dev 1999, 13:64-75.

12. Freedman SJ, Sun ZY, Kung AL, France DS, Wanger G, Eck MJ: Structural basis for negative regulation of hypoxia-inducible factor-I alpha by CITED2. Nat Struct Biol 2003, 10:504-5I 2 .

13. Yin Z, Haynie J, Yang X, Han B, Kiatchoosakun S, Restivo J, Yuan S, Prabhakar NR, Herrup K, Conlon RA, Hoit BD, Watanabe M, Yang YC: The essential role of Cited2, a negative regulator for HIF-I alpha, in heart development and neurulation. Proc Natl Acad Sci USA 2002, 99: 10488-10493.

14. Bragança J, Swingler T, Marques FI, Jones T, Eloranta JJ, Hurst HC, Shioda T, Bhattacharya S: Human CREB-binding protein/p300interacting transactivator with ED-rich tail (CITED) 4, a new member of the CITED family, functions as a co-activator for transcription factor AP-2. J Biol Chem 2002, 277:8559-8565.

15. Tien ES, Davis JW, Heuvel JP Vanden: Identification of the CREBbinding protein/p300-interacting protein CITED2 as a peroxisome proliferator-activated receptor alpha coregulator. J Biol Chem 2004, 279:24053-24063.

16. Chou YT, Wang H, Chen Y, Danielpour D, Yang YC: Cited2 modulates TGF-beta-mediated upregulation of MMP9. Oncogene 2006, 25:5547-5560.

17. Glenn DJ, Maurer RA: MRG I binds to the LIM domain of Lhx2 and may function as a coactivator to stimulate glycoprotein hormone alpha-subunit gene expression. J Biol Chem 1999, 274:36159-36167.

18. Andrews JE, O' Neill MJ, Binder M, Shioda T, Sinclair AH: Isolation and expression of a novel member of the CITED family. Mech Dev 2000, 95:305-308.

19. Gawantka V, Pollet N, Delius H, Vingron M, Pfister R, Nitsch R, Blumenstock C, Niehrs C: Gene expression screening in Xenopus identifies molecular pathways, predicts gene function and provides a global view of embryonic patterning. Mech Dev 1998, 77:95-141.

20. Ng PKS, Wu RS, Zhang ZP, Mok HOL, Randall DJ, Kong RYC: Molecular cloning and characterization of a hypoxia-responsive CITED3 cDNA from grass carp. Comp Biochem Physiol B Biochem Mol Biol 2003, 136:163-172.

21. Nikinmaa M, Rees BB: Oxygen-dependent gene expression in fishes. Am J Physiol Regul Integr Comp Physiol 2005, 288:R I079-I090.

22. Shi G, Boyle SC, Sparrow DB, Dunwoodie SL, Shioda T, de Caestecker MP: The transcriptional activity of CITEDI is regulated by phosphorylation in a cell cycle-dependent manner. J Biol Chem 2006, 281:27426-27435.

23. Law SHW, Wu RSS, Ng PKS, Yu RMK, Kong RYC: Cloning and expression analysis of two distinct HIF-alpha isoforms-gcHIF-Ialpha and gcHIF-4alpha--from the hypoxia-tolerant grass carp, Ctenopharyngodon idellus. BMC Mol Biol 2006, 7:15.

24. Rees BB, Bowman JA, Schulte PM: Structure and sequence conservation of a putative hypoxia response element in the lactate dehydrogenase-B gene of Fundulus. Biol Bull 200I, 200:247-25I.

25. Ema M, Hirota K, Mimura J, Abe H, Yodoi J, Sogawa K, Poellinger L, Fujii-Kuriyama $Y$ : Molecular mechanisms of transcription activation by HLF and HIFIalpha in response to hypoxia: their stabilization and redox signal-induced interaction with CBP/ p300. EMBO J 1999, 18:1905-1914. 
26. Fox SB, Bragança J, Turley H, Campo L, Han C, Gatter KC, Bhattacharya S, Harris AL: CITED4 inhibits hypoxia-activated transcription in cancer cells, and its cytoplasmic location in breast cancer is associated with elevated expression of tumor cell hypoxia-inducible factor I alpha. Cancer Res 2004, 64:6075-608I.

27. Yahata T, Takedatsu H, Dunwoodie SL, Braganca J, Swingler T, Withington SL, Hur J, Coser KR, Isselbacher KJ, Bhattacharya S, Shioda T: Cloning of mouse Cited4, a member of the CITED family p300/CBP-binding transcriptional coactivators: induced expression in mammary epithelial cells. Genomics 2002, 80:60I-6I3.

28. Stroka DM, Burkhardt T, Desbaillets I, Wenger RH, Neil DA, Bauer C, Gassmann M, Candinas D: HIF-I is expressed in normoxic tissue and displays an organ-specific regulation under systemic hypoxia. FASEB J 200I, I 5:2445-2453.

29. Rissanen E, Tranberg HK, Sollid J, Nilsson GE, Nikinmaa M: Temperature regulates hypoxia-inducible factor-I (HIF-I) in a poikilothermic vertebrate, crucian carp (Carassius carassius). J Exp Biol 2006, 209:994-1003.

30. Rees BB, Figueroa YG, Wiese TE, Beckman BS, Schulte PM: A novel hypoxia-response element in the lactate dehydrogenase-B gene of the killifish Fundulus heteroclitus. Comp Biochem Physiol A Mol Integr Physiol 2009, I 54:70-77.

31. Mole DR, Blancher C, Copley RR, Pollard PJ, Gleadle JM, Ragoussis J, Ratcliff PJ: Genome-wide association of hypoxia-inducible factor (HIF)-I\{alpha\} and HIF-2\{alpha\} DNA binding with expression profiling of hypoxia-inducible transcripts. J Biol Chem 2009, 284:16767-16775.

32. Benita Y, Kikuchi H, Smith AD, Zhang MQ, Chung DC, Xavier RJ: An integrative genomics approach identifies Hypoxia Inducible Factor-I (HIF-I)-target genes that form the core response to hypoxia. Nucleic Acid Res 2009, 37:4587-4602.

33. Haggerty TJ, Zeller KI, Osthus RC, Wonsey DR, Dang CV: A strategy for identifying transcription factor binding sites reveals two classes of genomic c-Myc target sites. Proc Natl Acad Sci USA 2003, 100:5315-5318.

34. Plisov S, Tsang M, Shi G, Boyle S, Yoshino K, Dunwoodie SL, Dawid IB, Shioda T, Perantoni AO, de Caestecker MP: Cited I is a bifunctional transcriptional cofactor that regulates early nephronic patterning. J Am Soc Nephrol 2005, 16: I 632-1644.

35. Bamforth SD, Bragança J, Eloranta JJ, Murdoch JN, Marques FIR, Kranc KR, Farza H, Henderson DJ, Hurst HC, Bhattacharya S: Cardiac malformations, adrenal agenesis, neural crest defects and exencephaly in mice lacking Cited2, a new Tfap2 co-activator. Nat Genet 200I, 29:469-474.

36. Bamforth SD, Bragança J, Farthing CR, Schneider JE, Broadbent $C$, Michell AC, Clarke K, Neubauer S, Norris D, Brown NA, Anderson $\mathrm{RH}$, Bhattacharya S: Cited2 controls left-right patterning and heart development through a Nodal-Pitx2c pathway. Nat Genet 2004, 36: I 189-1 196.

37. Yahata T, de Caestecker MP, Lechleider RJ, Andriole S, Roberts AB, Isselbacher KJ, Shioda T: The MSG I non-DNA-binding transactivator binds to the $\mathrm{p} 300 / \mathrm{CBP}$ coactivators, enhancing their functional link to the Smad transcription factors. J Biol Chem 2000, 275:8825-8834.

38. Webster WS, Abela D: The effect of hypoxia in development. Birth Defects Res C Embryo Today 2007, 81:215-228.

39. Zhang ZP, Wu RSS, Mok HOL, Wang YL, Poon WWL, Cheng SH, Kong RYC: Isolation, characterization and expression analysis of a hypoxia-responsive glucose transporter gene from the grass carp, Ctenopharyngodon idellus. Eur J Biochem 2003, 270:3010-3017.

40. Siegel S: Non-parametric statistics for the behavioral sciences New York: McGraw Hill; 1956.

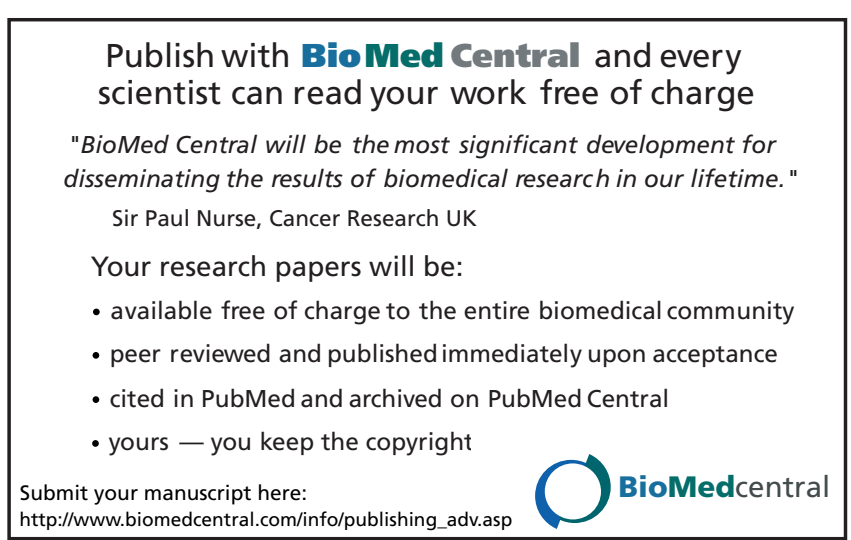

